\title{
O PROJETO DE EDUCAÇÃO INSTITUÍDO A PARTIR DE 1990: CAMINHOS PERCORRIDOS NA FORMAÇÃO DE PROFESSORES DE QUÍMICA NO BRASIL
}

\author{
Nyuara Araújo da Silva Mesquita*, Thiago Miguel Garcia Cardoso e Márlon Herbert Flora Barbosa Soares
}

Instituto de Química, Universidade Federal de Goiás, Campus II, CP 131, 74001-970 Goiânia - GO, Brasil

Recebido em 19/1/12; aceito em 3/7/12; publicado na web em 27/11/12

\begin{abstract}
EDUCATIONAL PROJECT RUN SINCE 1990: EDUCATIONAL PATHS FOLLOWED BY CHEMISTRY TEACHERS IN BRAZIL. This paper presents and discusses governmental approaches to teacher training introduced in 1990, whose focus is the education of chemistry teachers. Therefore, the aim of this study was to establish the relationship between legal aspects and background needs present in the Brazilian educational context, taking into account that the last two decades has seen a significant increase in the chemistry licensure courses offered by higher education institutions in Brazil. Discussing these aspects of chemistry teachers provides a reflection on the real background needs for this group of professionals.
\end{abstract}

Keywords: chemistry teacher education; legal aspects; teachers' background needs.

\section{INTRODUÇÃO}

Em trabalho anterior, ${ }^{1}$ discutimos alguns aspectos da história da Licenciatura em Química no Brasil de 1930 até 1980, no qual apresentamos os primeiros cursos de Licenciatura em Química no Brasil, além de discutirmos os aspectos políticos que influenciaram e direcionaram a formação docente em química no período. Neste trabalho, retomamos as discussões no contexto da formação de professores de Química que se estabeleceu no país no decorrer da implementação do projeto educacional desenhado a partir da década de 1990. Tais discussões tornam-se importantes na medida em que, a partir da década citada, houve toda uma proposta de implementação de mudanças nas diretrizes da educação básica, que reverberaram em modificações curriculares nos cursos de licenciatura.

Consideramos que ao explicitarmos as condições que influenciaram o processo de criação e expansão dos cursos de formação de professores em Química, podemos contribuir para um debate mais fundamentado, em termos teóricos, no sentido de refletirmos e repensarmos sobre a relação quantidade/qualidade nos cursos de formação inicial dos licenciados em Química. Dessa forma, buscamos descrever e discutir as questões legais e as possibilidades formativas desses licenciados que direcionaram e orientaram os referidos cursos de formação, no período citado.

As reformas educacionais da educação básica que se iniciaram na década de 1990 e se pautaram no modelo neoliberal de educação, findaram por atrelar as necessidades formativas do professor às demandas formativas da educação básica. ${ }^{2}$ Nesse contexto, todo o movimento de discussão sobre a formação de professores que foi desencadeado por entidades como a SBPC, a Associação Nacional pela Formação dos Profissionais da Educação (ANFOPE) e os Fóruns de Licenciatura desde o início da década de 1980, foi, de certa forma, arrefecido para que se tornasse realidade a adequação das políticas educacionais ao projeto de educação que contemplava a formação do indivíduo qualificado para o mercado de trabalho do mundo globalizado.

Essa visão a respeito das condições de construção de um projeto educacional pode ser encontrada no documento intitulado Proposta de Diretrizes para a Formação Inicial de Professores da Educação Básica, em Cursos de Nível Superior: ${ }^{3}$

A internacionalização da economia confronta o Brasil com

*e-mail: nyuara@quimica.ufg.br os problemas da competitividade para a qual a existência de recursos humanos qualificados é condição indispensável. Quanto mais a sociedade brasileira consolida as instituições políticas democráticas, fortalece os direitos da cidadania e participa da economia mundializada, mais se amplia o reconhecimento da importância da educação na sociedade do conhecimento. (p. 507)

A partir dessa visão de necessidade formativa para que o sujeito esteja inserido no mundo globalizado, as políticas de governo sustentaram suas metas para a construção de um projeto educacional que atendesse às exigências dos órgãos internacionais financiadores da reforma da educação brasileira. Nesse cenário, a formação de professores apresentou-se como assunto que previa soluções em âmbito restrito sem se considerar que tal formação deveria privilegiar um conhecimento amplo não apenas de conteúdo, mas também politizado e crítico. Mello ${ }^{4}$ explicita bem esse modo de pensar a formação de professores:

A mudança nos cursos de formação inicial de professores terá de corresponder, em extensão e profundidade, aos princípios que orientam a reforma da educação básica, mantendo com esta sintonia fina. Não se trata de criar modismos, mas de buscar modalidades de organização pedagógica e espaços institucionais que favoreçam a constituição, nos futuros professores, das competências docentes que serão requeridas para ensinar e fazer com que os alunos aprendam de acordo com os objetivos e diretrizes pedagógicas traçados para a educação básica. (p. 101)

Pode ser identificada na concepção sobre formação de professores apresentada por Mello, ${ }^{4}$ a compreensão que conduziu à construção das orientações e diretrizes para a formação de professores, sempre aliando estas aos princípios norteadores da educação básica, dentre eles: currículo por competências e formação para o mercado de trabalho. Lembramos que o discurso presente nos documentos orientadores da educação básica refere-se à inserção do estudante no mundo do trabalho por meio de uma "formação para a vida", porém associa discursos proeminentemente eficientistas nos quais "a vida assume dimensão especialmente produtiva do ponto de vista econômico, em detrimento de sua dimensão cultural mais 
ampla". ${ }^{5}$ Ao discutir a questão da inserção do termo competência no discurso oficial da formação de professores no Brasil, Dias ${ }^{6}$ traz as seguintes ponderações:

Nesse processo, importa que o sujeito se prepare para viver em um mundo mais competitivo, no qual o desenvolvimento da empregabilidade torna-se vital. Esse processo de formação deve ser construído pelo próprio sujeito e deve ter caráter permanente, é o aprender a aprender. Destacam-se ainda como elementos desse discurso curricular a avaliação do desempenho, a promoção dos professores por mérito, o desenvolvimento da produtividade visando à eficácia do sistema bem como do trabalho docente. (p. 4)

Estes são aspectos que se mostram importantes para fundamentar nossas discussões, já que buscaremos a seguir deslindar alguns pontos importantes a partir dos quais se organizaram e se organizam os cursos de licenciatura em Química no país a partir da década de 1990.

\section{ASPECTOS LEGAIS}

Com a entrada em vigor da Lei de Diretrizes e Bases da Educação Nacional - Lei 9.394/96 - tornou-se requisito mínimo para a docência no ensino básico a formação em curso de licenciatura, de graduação plena, em Universidades e Institutos Superiores de Educação. ${ }^{7}$ Considera-se esta mudança um ganho para os profissionais da educação ressaltando-se que na lei anterior a esta, 5.692/71, não havia a obrigatoriedade de formação plena em nível superior para o professor do ensino básico. O decreto 3.276, de 06/12/1999, ${ }^{8}$ veio complementar a questão da formação de professores com o seguinte texto em seu parágrafo $4^{\circ}$ :

A formação de professores para atuação em campos específicos do conhecimento far-se-á em cursos de licenciatura, podendo os habilitados atuar, no ensino de sua especialidade, em qualquer etapa da educação básica.

Ao tratar especificamente a formação de professores de Química, percebe-se que a exigência presente na Lei 9.394/96 gerou um aumento na demanda por cursos de licenciatura em Química. Cita-se como exemplo a criação destes cursos no Estado de Goiás que, até 1996, contava apenas com o curso de licenciatura em Química oferecido pela Universidade Federal de Goiás em Goiânia e, atualmente, há a oferta deste curso em 19 instituições de nível superior, dentre as quais, 15 são instituições públicas (entre universidades e institutos federais) e 4 são privadas.

Embora tenha havido um aumento na oferta de cursos, deve existir a preocupação com a qualidade da formação docente, pois, na contramão das políticas neoliberais de critério economicista para a educação, precisamos pensar a escola como espaço tanto de elaboração de novos conhecimentos quanto como transformadora da realidade histórica dos indivíduos. Para Noronha: ${ }^{9}$

O professor precisa ser mediador ativo e crítico na tarefa permanente de reinterpretar os conhecimentos históricos da humanidade. Portanto, não é qualquer profissional, com uma formação aligeirada que poderá desempenhar essa tarefa. A valorização do trabalho do professor é o eixo central para se elevar o estatuto da profissionalidade deste agente histórico da educação dando destaque tanto à sua identidade epistemológica quanto aos saberes da docência. (p. 117)
O efeito, aparentemente positivo da obrigatoriedade da formação superior para o docente do ensino básico trouxe consigo algumas consequências não tão positivas, como relatam Frigotto e Ciavatta ${ }^{10}$ ao afirmarem que não houve aumento de vagas no ensino superior gratuito, em algumas regiões houve até diminuição, e dilatou-se de forma exponencial a indústria do diploma nas instituições privadas, semelhantemente ao que aconteceu nas décadas de 1960 e 1970 com os cursos de formação de professores.

No final da década de 1990, porém, o governo federal buscou uma saída em relação a este aspecto ao incentivar os Centros Federais de Educação Tecnológica, antigos CEFET, atuais Institutos Federais de Educação, Ciência e Tecnologia (IF) a criarem cursos de licenciaturas para atenderem às demandas de formação de professores. $\mathrm{O}$ decreto que previa esta inserção dos CEFET no sistema federal de formação de professores (2.406/97) foi reformulado e apresentou a seguinte redação no Decreto 3.462/00: ${ }^{11}$

Art. $1^{\circ} \mathrm{O}$ art. $8^{\circ}$ do Decreto no 2.406, de 27 de novembro de 1997, passa a vigorar com a seguinte redação: “Art. 8o Os Centros Federais de Educação Tecnológica, transformados na forma do disposto no art. 3o da Lei no 8.948, de 1994, gozarão de autonomia para a criação de cursos e ampliação de vagas nos níveis básico, técnico e tecnológico da Educação Profissional, bem como para implantação de cursos de formação de professores para as disciplinas científicas e tecnológicas do Ensino Médio e da Educação Profissional.

Houve um empenho significativo desta rede federal de ensino na implantação das licenciaturas tanto que, de acordo com levantamento feito por Franco e Pires, ${ }^{12}$ em 2008 os atuais IF contavam com os cursos de licenciatura, listados na Tabela 1.

Tabela 1. Oferta de cursos de Licenciatura pelos IF em 2008

\begin{tabular}{lc}
\hline Cursos de Licenciatura & Número de cursos oferecidos \\
\hline Física & 12 \\
Matemática & 18 \\
Química & 15 \\
Biologia & 6 \\
Outras áreas (Educação Física, Infor- & 14 \\
mática, Construção Civil, Eletricidade, & \\
Mecânica, Geografia e Espanhol) & \\
\hline
\end{tabular}

Fonte: ref. 12

De acordo com levantamento mais recente realizado na base de dados do site do Ministério da Educação (MEC), podemos observar na Figura 1S, material suplementar, a quantidade de cursos de Licenciatura em Química oferecidos pelos IF. Em 2011, já existia um total de 58 cursos em 2011, ou seja, de 2008 a 2011 foram criados 43 cursos de Licenciatura em Química.

De acordo com as orientações legais no âmbito dos recém-criados IF, mantém-se o direcionamento para que as instituições estimulem a criação de cursos de licenciatura, pois de acordo com o Decreto 6.095 de 2007 que estabelece diretrizes para o processo de integração de instituições federais de educação tecnológica, para fins de constituição dos Institutos Federais de Educação, Ciência e Tecnologia - IFET, no âmbito da Rede Federal de Educação Tecnológica, os Institutos devem destinar o mínimo de $20 \%$ da sua dotação orçamentária para a consecução do objetivo de oferecer "cursos de licenciatura, bem como programas especiais de formação pedagógica, com vista à formação de professores para a educação básica, sobretudo nas áreas de ciências e matemática, de acordo com as demandas de âmbito local e regional". ${ }^{13}$ 
A questão da quantidade tem sido, de certa forma, resolvida por meio da criação de cursos de licenciatura em Física e Química, porém há uma discussão maior que precisa ser feita relacionada à própria identidade destas instituições, que têm sua origem em ideais de formação para profissionais de áreas específicas e tecnológicas.

Porém, o cuidado em termos de formação de professores nesse caso, quando consideramos a profusão de cursos de licenciatura nos IF está relacionada ao profissional a ser contratado para tais cursos. Apesar da exigência da licenciatura, não temos educadores químicos suficientes nem mesmo para os cursos já existentes no país. Com o surgimento de tais licenciaturas, a situação parece ficar mais caótica, crescendo a possibilidade dos estágios e das disciplinas específicas da área de formação do licenciando ficarem a cargo de professores das demais áreas da Química, que podem até se armar do esforço necessário, mas não têm a formação.

Além da expansão dos IF, há também o programa de Reestruturação e Expansão das Universidades Federais (REUNI) do governo federal que prevê até 2012 a criação de mais 267 cursos de licenciatura em relação ao ano de 2008, como pode ser observado na Figura 1.

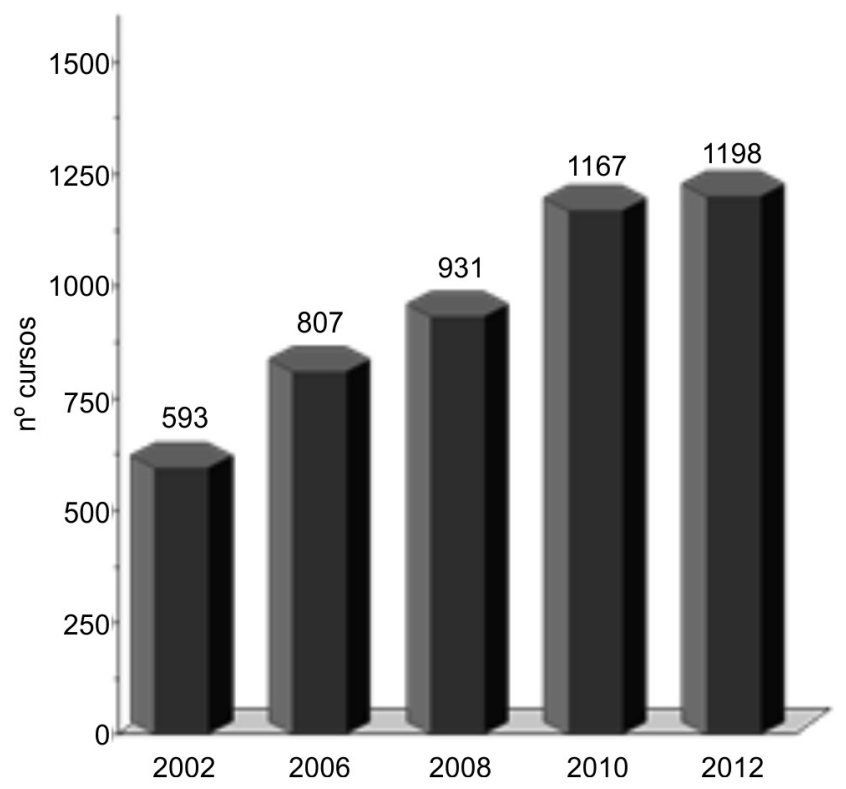

Figura 1. Proposta REUNI de expansão dos cursos de licenciatura Fonte: http://reuni.mec.gov.br/index.php?option=com_content\&task=view\&id=148\& Itemid $=8$

De acordo com o que pode ser observado a partir das ações governamentais houve, a partir de 2010, a preocupação em priorizar as questões quantitativas da formação de professores. Temos claro, porém, a necessidade de que estas implementações estejam acompanhadas da preocupação com a qualidade e o nível de formação destes professores, contrapondo-se a outros tipos de cursos que surgiram para atender à necessidade legal do diploma de licenciado para o exercício do magistério na Educação Básica.

Sob este enfoque, argumentamos a importância da discussão sobre os cursos chamados aligeirados, ou seja, aqueles que, visando à formação em serviço, permitem a habilitação em cursos de licenciatura aos finais de semana ou durante o período de férias. Este aspecto da formação docente encontra respaldo legal no item II do artigo 63 da LDB 9394/96 com a seguinte redação:

Art. 63. Os institutos superiores de educação manterão: I cursos formadores de profissionais para a educação básica, inclusive o curso normal superior, destinado à formação de docentes para a educação infantil e para as primeiras séries do ensino fundamental; II - programas de formação pedagógica para portadores de diplomas de educação superior que queiram se dedicar à educação básica; III - programas de educação continuada para os profissionais de educação dos diversos níveis. ${ }^{7}$

Melo $^{14}$ alerta para os perigos que a legislação pode trazer em relação à formação de professores, apontando algumas contradições presentes na lei. A abertura para que instituições ofereçam cursos aligeirados pode causar o esvaziamento das licenciaturas com a "transformação" de graduados em professores, de forma rápida, por meio de cursos de complementação pedagógica. Mais especificamente, a autora enfatiza que os programas de formação estão claramente dotados de um leque de opções, que "tem possibilitado que a consecução das políticas de governo seja marcada pela fragmentação e pelo aligeiramento, não apenas no aspecto organizativo e temporal, mas também no tocante ao aprofundamento de conteúdos e à apropriação de competências".

Tendo em vista a possibilidade legal de oferta de tais cursos, muitas instituições adotaram a ideia com a justificativa da necessidade de se habilitar professores em serviço, que já portavam diplomas de formações diversas. A própria LDB mostra-se instrumento de pressão quando, no parágrafo 4 do artigo 87 das Disposições Transitórias traz o seguinte texto: "até o fim da Década da Educação somente serão admitidos professores habilitados em nível superior ou formados por treinamento em serviço". ${ }^{7}$

Cabe-nos refletir sobre o aspecto de quem realmente aligeira: a lei ou as instituições. A possibilidade prevista em lei não nos fala em aligeiramento, apenas sinaliza no sentido de proporcionar, àqueles que já possuem determinada habilitação, a complementação de estudos em programas de formação pedagógica para o exercício do magistério. A questão é que, ao assumirem esta tarefa, algumas instituições não atentam à qualidade da formação docente, fazendo com que este contexto formativo se configure mais como um apêndice de outra categoria de formação do que uma formação específica da área de educação. Tais ideias nos remetem às medidas emergenciais para a formação de professores tomadas na década de 1970, como os projetos chamados Esquemas I e II e licenciaturas curtas em ciências.

O Esquema I consistia em um curso de complementação pedagógica de $600 \mathrm{~h}$ para profissionais portadores de diploma de grau superior e o Esquema II contemplava uma complementação pedagógica de 1080, 1200 ou $1480 \mathrm{~h}$ para portadores de diploma de nível técnico ou médio que pretendiam atuar na área de ensino. As licenciaturas curtas em ciências foram regidas pela resolução 30/75 e habilitavam o professor formado para atuação no curso ginasial. ${ }^{1}$ Estes projetos formativos ainda persistiram no Brasil até a década de 1990.

\section{POSSIBILIDADES FORMATIVAS ATUAIS}

Uma questão importante que deve ser pontuada em nossa discussão é a criação do Sistema Universidade Aberta do Brasil (UAB) criado pelo Ministério da Educação, em 2005. Este sistema tem como objetivo implantar cursos na modalidade de educação à distância, com a finalidade expandir e interiorizar a oferta de cursos e programas de educação superior, além de ampliar o acesso à educação superior pública, levando tais cursos às diferentes regiões do país.

De acordo com dados da Coordenação de Aperfeiçoamento do Pessoal de Nível Superior (CAPES), já existem 23 cursos de licenciatura em Química cadastrados no UAB, todos oferecidos por instituições públicas de ensino superior. Dentre elas, podemos citar a Universidade Federal do Rio Grande do Norte, a Universidade Federal do Rio de Janeiro, o Instituto Federal de Ciência e Tecnologia do 
Mato Grosso e a Universidade Federal de Alfenas. Por tratar-se de uma implantação recente, não há ainda dados na literatura da área de ensino de ciências que possam nos indicar questões referentes à qualidade formativa destes cursos, no entanto, podemos argumentar que para um curso de licenciatura em Química que envolve, no mínimo, uma infraestrutura básica em termos de laboratório, as questões de educação à distância precisam ser pensadas de maneira cuidadosa para que a formação básica do licenciado não seja comprometida.

Ao discutirmos a diversidade de modelos de licenciaturas em Química, sejam eles presenciais, à distância ou aligeirados, oferecidos por instituições privadas ou públicas, os aspectos da natureza do conhecimento relacionados à formação proporcionada aos futuros profissionais da docência precisam ser revistos e a questão da qualidade do curso deve ser uma discussão constante. Nesse sentido, devemos considerar que a construção dos saberes efetivamente importantes para a adequação destes cursos às tendências atuais de formação de professores não pode acontecer independentemente da discussão sobre qual o modelo de formação docente a ser utilizado no contexto atual da educação brasileira.

Dentre estas tendências atuais de formação de professores, discutiremos a tentativa de superação do modelo de formação baseada na racionalidade técnica; a seguir, abordaremos a racionalidade técnica $\mathrm{x}$ racionalidade prática e, depois, a formação pela pesquisa inserida nos direcionamentos legais para formação de professores.

Adotada como modelo de formação de professores, a racionalidade técnica não articula conhecimentos teóricos à prática efetiva da sala de aula. Isto pode ser observado nos currículos $3+1$, em que só ao final dos cursos os estudantes têm acesso ao desenvolvimento de atividades na escola campo por meio do estágio. Segundo Lobo e Moradillo: ${ }^{15}$

Esse modelo considera necessário um conhecimento teórico sólido que constitua a base para que o profissional atue na prática, ou seja, a prática passa a se constituir no campo da aplicação de conhecimentos teóricos. Uma formação docente calcada nesse modelo concebe a prática como um mundo à parte, separado do campo teórico, normalmente idealizado. (p. 39)

Existe a tentativa de mudança neste aspecto, a partir dos documentos oficiais que orientam e estabelecem as diretrizes para a formação de professores no Brasil. Segundo essas diretrizes, a inserção do estágio deve-se dar a partir da segunda metade dos cursos de licenciatura: ${ }^{16}$

Art. $1^{\circ}$ A carga horária dos cursos de Formação de Professores da Educação Básica, em nível superior, em curso de licenciatura, de graduação plena, será efetivada mediante a integralização de, no mínimo, 2800 h, nas quais a articulação teoria-prática garanta, nos termos dos seus projetos pedagógicos, as seguintes dimensões dos componentes comuns: I - 400 h de prática como componente curricular, vivenciadas ao longo do curso; II - 400 h de estágio curricular supervisionado a partir do início da segunda metade do curso; III - 1800 h de aulas para os conteúdos curriculares de natureza científico-cultural; IV - 200 h para outras formas de atividades acadêmico-científico-culturais. (grifo dos autores)

Esta orientação é importante na medida em que possibilita maior interação entre teoria e prática no decorrer do curso. No entanto, tal orientação, por si só, não garante problematizar as vivências profissionais e convertê-las em material de reflexão da prática pedagógica do futuro professor. A formação docente que leva em consideração a atitude reflexiva do sujeito a partir das situações da vivência e da prática pedagógica encontra respaldo no modelo de formação docente chamado de racionalidade prática. Esta formação implica em concepções que procuram levar em conta a complexidade da ação docente, buscando um estreitamento entre os saberes vindos da academia e aqueles provenientes da vivência dos professores em serviço. A partir da intersecção destes diferentes saberes, constrói-se um saber distinto. ${ }^{17}$

Ao criticar o modelo da racionalidade técnica, Schön ${ }^{18}$ propõe a epistemologia da prática por meio da reflexão sobre a ação:

Quando um profissional reflete desde e sobre sua prática, os possiveis objetos de sua reflexão são tão variados como os tipos de fenômenos e os sistemas de saber da prática que ele conhece. Pode refletir sobre os padrões e as avaliações em um julgamento tácito subjacente, ou sobre as estratégias e teorias implícitas em um padrão de conduta. Pode pensar sobre os sentimentos em relação a uma situação que o levou a adotar um determinado curso de ação, sobre a maneira com que ele enquadra o problema que está tentando resolver, ou sobre o papel que construiu para si próprio dentro de um contexto institucional mais amplo. A reflexão da ação, nestas diversas formas, é central para a arte através da qual, por vezes, os profissionais se adequam a situações desconfortáveis na prática. (p. 67)

Nas licenciaturas em Química, nosso foco atual de estudo, a ideia da prática reflexiva em substituição ao modelo formativo da racionalidade técnica pode ser encontrada na visão do professor que investiga e reflete sobre sua própria prática, conforme apresentado por Scalcon ${ }^{19}$ ao discutir as recentes tendências formativas para a docência no século XXI:

Entendendo que a tônica da formação de professores deva concentrar-se na própria prática, essa nova perspectiva também é fortemente caracterizada pelo conceito de prática reflexiva segundo a qual os professores seriam capazes de realizar uma auto-reflexão de si e de suas práticas de modo que essa mesma prática fosse o lugar original tanto da formação quanto da produção de saberes relativos à profissão. (p. 118)

Em nossa compreensão, a adoção deste modelo de formação docente pode significar uma maior atenção ao espaço dos estágios supervisionados na construção dos saberes docentes durante a formação inicial, pois é durante a realização dos estágios que o estudante tem o primeiro contato com as situações que permeiam a prática docente. Vemos aí a oportunidade de construção e elaboração de conhecimentos a partir da interação entre teoria e prática no desenvolvimento dos licenciandos enquanto sujeitos do processo formativo em questão.

Defendemos ainda que, para que o processo de formação de professores mediante o uso da racionalidade prática se efetive, precisamos estar atentos ao fato de que não é simplesmente a prática pela prática, mas deve-se objetivar a formação de um sujeito crítico e consciente da sua realidade profissional sendo este capaz, ao mesmo tempo, de argumentar e intervir quando sua realidade assim o exigir.

Podemos fundamentar essa ideia nas reflexões de Pérez Gomez ${ }^{20}$ ao expor que embora a prática seja considerada em seu papel central no currículo de formação de professores, esta prática precisa desencadear a reflexão dos sujeitos em uma atitude investigativa sobre o processo desenvolvido. Esta ação questionadora do sujeito requer alguém que saiba pensar e saiba aprender a aprender, ou seja, a pesquisa está alicerçada na emancipação de quem a desenvolve, 
uma vez que possibilita a este sujeito se perceber capaz de criar oportunidades e fazer história. ${ }^{21}$

Os contextos de formação de professores por meio da racionalidade prática e da reflexão sobre a ação podem ser considerados contextos indissociáveis, tendo em vista o fato de que um complementa o outro e ambos podem se associar ao contexto da formação pela pesquisa, no sentido de possibilitar uma visão formativa que contemple as atuais tendências de construção dos saberes docentes.

No documento intitulado Diretrizes Curriculares Nacionais para a Formação de Professores da Educação Básica, em nível superior, curso de licenciatura, de graduação plena, ${ }^{22}$ as orientações para a formação destes profissionais fazem uso dos contextos apresentados, como se pode perceber nos seguintes trechos:

Art $3^{\circ}$ - A formação de professores que atuarão nas diferentes etapas da educação básica observará princípios norteadores desse preparo para o exercício profissional específico, que consideram: [...] III-A pesquisa como foco no processo ensino aprendizagem, uma vez que ensinar requer, tanto dispor de conhecimentos e mobilizá-los para a ação, como compreender o processo de construção do conhecimento [...] Parágrafo único: a aprendizagem deverá ser orientada pelo princípio metodológico geral, que pode ser traduzido pela ação-reflexão-ação e que aponta a resolução de situações- problema como uma das estratégias didáticas privilegiadas. [...] Art. 13 parágrafo primeiro: A prática será desenvolvida com ênfase nos procedimentos de observação e reflexão, visando a atuação em situações contextualizadas, com o registro dessas observações realizadas e a realização de situações-problema. (grifo dos autores)

Consideremos agora uma observação para além do discurso explicitado nos documentos. As tendências e direcionamentos apresentados se colocam como caminhos recentes para a formação de professores. Vivenciamos ainda um período de transição no qual as tendências estão postas nas diretrizes oficiais, mas em decorrência da carência de profissionais habilitados, professores formadores, para conduzirem os processos de formação inicial nos moldes das tendências apresentadas nos documentos, há ainda um longo caminho a percorrer. Porém, há que se refletir sobre este fator de importante influência neste cenário: o papel e a qualificação do professor formador de professores de Química. Para Maldaner, ${ }^{23}$ faltam profissionais com o perfil necessário à concretização das propostas de formação do educador químico para a educação básica. Segundo ele:

Há, por exemplo, grande dificuldade na aceitação da implementação das $400 \mathrm{~h}$ de Práticas Pedagógicas e $400 \mathrm{~h}$ de Estágio Supervisionado nas licenciaturas, que são tempos e espaços de formação, ou poderiam ser, privilegiados para veicular e desenvolver os conhecimentos relacionados ao educador químico. Esbarra-se, neste momento novo das licenciaturas, na falta de profissionais para ocupar esses tempos e espaços com competência necessária. A chamada para os concursos revela isso! Onde se encontram os educadores químicos em número e com preparo suficientes para desencadear práticas que despertem o interesse, o debate, a produção científica e acadêmica de qualidade que os torne imprescindiveis no contexto de formação dos professores, para todos os níveis em que deverá acontecer? Respondo com firmeza: eles não existem. Temos que formá-los. (p. 274)

Este processo de formação será ainda longo, tendo em vista o fato de não haver, ainda consolidado no país, um programa específico de formação de doutores na área de ensino de Química. Essa formação de doutores na área acontece nas faculdades de educação, em programas de pós-graduação que contam com linhas temáticas de pesquisa no Ensino de Ciências e Matemática.

Há ainda poucos doutorados em ensino de ciências, 13 ao todo que aceitam licenciados em química. No entanto, não há um mestrado ou um doutorado em ensino de química, especificamente. Os doutorados em ensino de ciências vinham sendo uma recomendação da extinta área 46 da CAPES, no sentido de que os doutores em ensino de química, biologia ou física fossem formados em um doutorado que os congregasse, evitando-se assim uma fragmentação da área das ciências.

Alguns programas, como o do Instituto de Química da UFG (Programa Multi-institucional UFG/UFMS/UFU) e o do Departamento de Química da UFSCar, por exemplo, oferecem entre suas linhas de pesquisa a Educação Química. Porém, nesses casos são muitas as dificuldades. Dentre estas podemos citar a falta de disciplinas específicas da área e a dificuldade de diálogo entre os pares no próprio grupo de docentes, já que são poucos da área de ensino de química orientando nesses programas. No caso específico do IQ - UFG são apenas 2 orientadores para atender a grande procura de mestres que querem dar continuidade à formação acadêmica na área de Ensino de Química em Goiás e no Centro-Oeste.

O momento novo das licenciaturas, ao qual se referiu Maldaner ${ }^{23}$ na citação anterior, deve-se, em parte, às reformas educacionais implementadas pela Lei 9394/967 e que se refletiram nos documentos orientadores da educação nacional de nível básico, os Parâmetros Curriculares Nacionais para o Ensino Médio (PCNEM) e as Orientações Curriculares para o Ensino Médio (OCEM). Salientamos que a produção destes documentos está ligada aos pesquisadores de educação química no Brasil que participaram da elaboração de tais documentos, levando em consideração os resultados de suas pesquisas. ${ }^{24}$

Os princípios constitutivos do ensino de Química no nível médio passaram a ser considerados importantes aspectos formativos no contexto da formação de professores de Química. Desta forma, se tornaram presentes de maneira efetiva nas licenciaturas em Química temas como CTS (ciência tecnologia e sociedade), contextualização e interdisciplinaridade. As diretrizes para formação de professores também incorporam tais temas, o que decorre da questão de que, para ensinar Química no nível básico de ensino de acordo com as diretrizes oficiais, é preciso que o professor, em princípio, esteja preparado pedagogicamente em tais aspectos.

No cenário de implementação de propostas atuais para formação de educadores químicos, os cursos de licenciatura nesta área buscam uma organização curricular que contemple atender às demandas oficiais. Os cursos apresentam esta forma de organização por meio do seu Projeto Pedagógico de Curso (PPC), onde as disciplinas são geralmente organizadas em núcleos que compreendem basicamente as disciplinas específicas do conhecimento químico e as disciplinas de cunho pedagógico. Estas fazem parte da dimensão de natureza científico-cultural proposta na Resolução $\mathrm{CNE} / \mathrm{CP} \mathrm{n}^{\circ} 2$ que institui a carga horária e duração dos cursos de licenciatura. A carga horária relacionada a estas disciplinas é estabelecida em um mínimo de 1800 h. $^{16}$

As disciplinas que fazem a ponte entre os núcleos científico e pedagógico estão inseridas, em termos da resolução citada, nas dimensões de prática como componente curricular, com $400 \mathrm{~h}$, e de estágio, também com $400 \mathrm{~h}$. É nesse contexto que tanto o estágio quanto as disciplinas de prática de ensino de Química assumem a tarefa de estabelecer situações de interação que possibilitem um saber articulado em diferentes âmbitos do conhecimento profissional.

No entanto, dada a questão da construção singular dos projetos pedagógicos em decorrência dos diferentes contextos de cursos de 
licenciatura em Química, muitas são as diferenças no quesito distribuição de carga horária. Ao investigar o espaço da prática de ensino e do estágio curricular nos cursos de formação de professores de Química das IES públicas paulistas Kasseboehmer e Ferreira ${ }^{25}$ analisam que:

Nas disciplinas destinadas à formação pedagógica do licenciando, também ocorrem diferenças. Entretanto, é possível observar que estas disciplinas constituem uma porcentagem relativamente baixa do total do conteúdo científico-cultural. Esta é uma face importante da formação do licenciando, mas que não parece ser compreendida dessa maneira por algumas instituições. (p. 696)

As observações feitas pelos autores nos mostram como os cursos se organizam ao interpretar documentos e ressignificá-los na execução de uma proposta. A partir de tal observação, é importante pontuarmos que para que se estabeleça uma compreensão mais ampla acerca do contexto das licenciaturas em Química torna-se necessário um movimento de questionamento e aprofundamento sobre os PPC das licenciaturas em Química.

Em termos de investigação acerca da formulação e implementação de propostas para cursos de licenciatura em Química, nos apropriamos do conceito estabelecido por Veiga, ${ }^{26}$ que busca na origem da palavra projeto o sentido do uso da mesma no cenário de políticas públicas para a educação. Segundo a autora, a palavra vem do latim projice$r e$, que significa "dirigir-se para o futuro" ou "lançar-se na direção do possível". Sendo assim, é o futuro que deve orientar e conduzir nossas ações do presente, porém precisamos estar atentos às questões históricas que envolveram e envolvem o processo de construção dos projetos de formação de professores de Química no sentido de que não se repitam erros que redundem em propostas formativas defasadas e/ou inadequadas às questões atuais da educação.

\section{CONSIDERAÇÕES FINAIS}

O projeto educacional brasileiro instituído a partir da década de 1990 associou a formação de professores especificamente às diretrizes propostas para a educação básica. Sob tal enfoque, as licenciaturas em geral sofreram um "empobrecimento" no sentido de restringir o contexto formativo aos aspectos orientadores da educação básica, deixando de lado discussões importantes como as políticas públicas de formação de professores e questões éticas relacionadas à atuação docente.

As licenciaturas em Química enfrentam diversos problemas, mesmo considerando o fato de que houve um aumento significativo na quantidade de cursos oferecidos no país. Dentre tais problemas, a falta de professores formadores no âmbito da Educação em Química pode comprometer propostas formativas que considerem em seus eixos formativos os resultados das pesquisas desenvolvidas pelos pesquisadores da área nos últimos 30 anos.

Nesse momento em que são discutidas situações de melhoria da qualidade da formação superior no Brasil, torna-se importante que os educadores químicos considerem repensar as licenciaturas em Química, no sentido de possibilitar e promover uma formação inicial que contemple tanto as questões políticas e éticas quanto as questões epistemológicas inerentes à essa área do saber.

\section{REFERÊNCIAS}

1. Mesquita, N. A. S.; Soares, M. H. F. B.; Quim. Nova 2011, 34, 165.

2. Freitas, H. C. L.; Educ. Soc. 2002, 23, 136.

3. http://w3.ufsm.br/coordmat/arquivos/Formacao_inicial.pdf, acessada em Maio 2011.

4. Mello, G. N.; São Paulo em Perspectiva 2000, 14, 98.

5. Lopes, A.; Educ. Soc. 2002, 23, 386.

6. Dias, R. E.; DataGramaZero - Revista de Ciência da Informação 2003, 4,4 .

7. Brasil; Lei de Diretrizes e Bases da Educação Nacional, Lei $n^{\circ} 9394$, de 20/12/1996.

8. http://www.planalto.gov.br/ccivil_03/decreto/D3276.htm, acessada em Maio 2011.

9. Noronha, O. M.; Políticas neoliberais, conhecimento e educação, Alínea: Campinas, 2002.

10. Frigotto, G.; Ciavatta, M.; Ensino Médio: ciência, cultura e trabalho, MEC, SEMTEC: Brasília, 2004.

11. http://www.prolei.inep.gov.br/anexo.do?URI=http $\% 3 \mathrm{~A} \% 2 \mathrm{~F} \% 2 \mathrm{Fwww}$. ufsm.br\%2Fcpd\%2Finep\%2Fprolei\%2FAnexo\%2F-906592828 3546033347, acessada em Setembro 2010.

12. Franco, R. Z.; Pires, L. L. A.; Anais do XVIII Simpósio Nacional de Ensino de Física, Vitória, Brasil, 2009.

13. http://www.soleis.com.br/D6095.htm, acessada em Setembro 2009.

14. Melo, M. T. L.; Educ. Soc. 1999, 20, 45.

15. Lôbo, S. F.; Moradillo, E. F.; Química Nova na Escola 2003, 17, 39.

16. http://portal.mec.gov.br/cne/arquivos/pdf/CP022002.pdf, acessada em Maio 2011.

17. Rosa, M. I. F. P.; Sene, I. P.; Parma, M.; Quintino, T. C. A.; Rev. Bras. Pesq. Educ. Ciênc. 2003, 3, 58.

18. Schön, D.; El profesional reflexivo: como piensan los profesionales cuando actúan, Ediciones Paidós Ibérica: Barcelona, 1998.

19. Scalcon, S. Em Políticas educacionais e práticas pedagógicas para além da mercadorização do conhecimento; Almeida, M., org.; Alínea: Campinas, 2005, cap. 6.

20. Gomez, A. P. Em Os professores e a sua formação; Nóvoa, A., org.; Publicações Dom Quixote: Lisboa, 1995, cap. 5.

21. Galiazzi, M. C.; Revista Eletrônica do Mestrado em Educação Ambiental 2001, 6.

22. http://portal.mec.gov.br/seesp/arquivos/pdf/res1_2.pdf, acessada em Maio 2011

23. Maldaner, O. A. Em Educação Química no Brasil: memórias, políticas e tendências; Rosa, M. I. P.; Rossi, A. V., orgs.; Editora Átomo: Campinas, 2008, cap. 13.

24. Zanon, L. B.; Maldaner, O. A., orgs.; Fundamentos e Propostas de Ensino de Química para a Educação Básica no Brasil, Editora Unijuí: Ijuí, 2007.

25. Kassemboehmer, A. C.; Ferreira, L. H.; Quim. Nova 2008, 31, 694.

26. Veiga, I. P.; Educação Básica e Educação Superior: Projeto PolíticoPedagógico, Papirus: Campinas, 2004. 
O PROJETO DE EDUCAÇÃO INSTITUÍDO A PARTIR DE 1990: CAMINHOS PERCORRIDOS NA FORMAÇÃO DE PROFESSORES DE QUÍMICA NO BRASIL

Nyuara Araújo da Silva Mesquita*, Thiago Miguel Garcia Cardoso e Márlon Herbert Flora Barbosa Soares Instituto de Química, Universidade Federal de Goiás, Campus II, CP 131, 74001-970 Goiânia - GO, Brasil

\section{Cursos de Licenciatura em Química em Institutos Federais por estados da federação.}

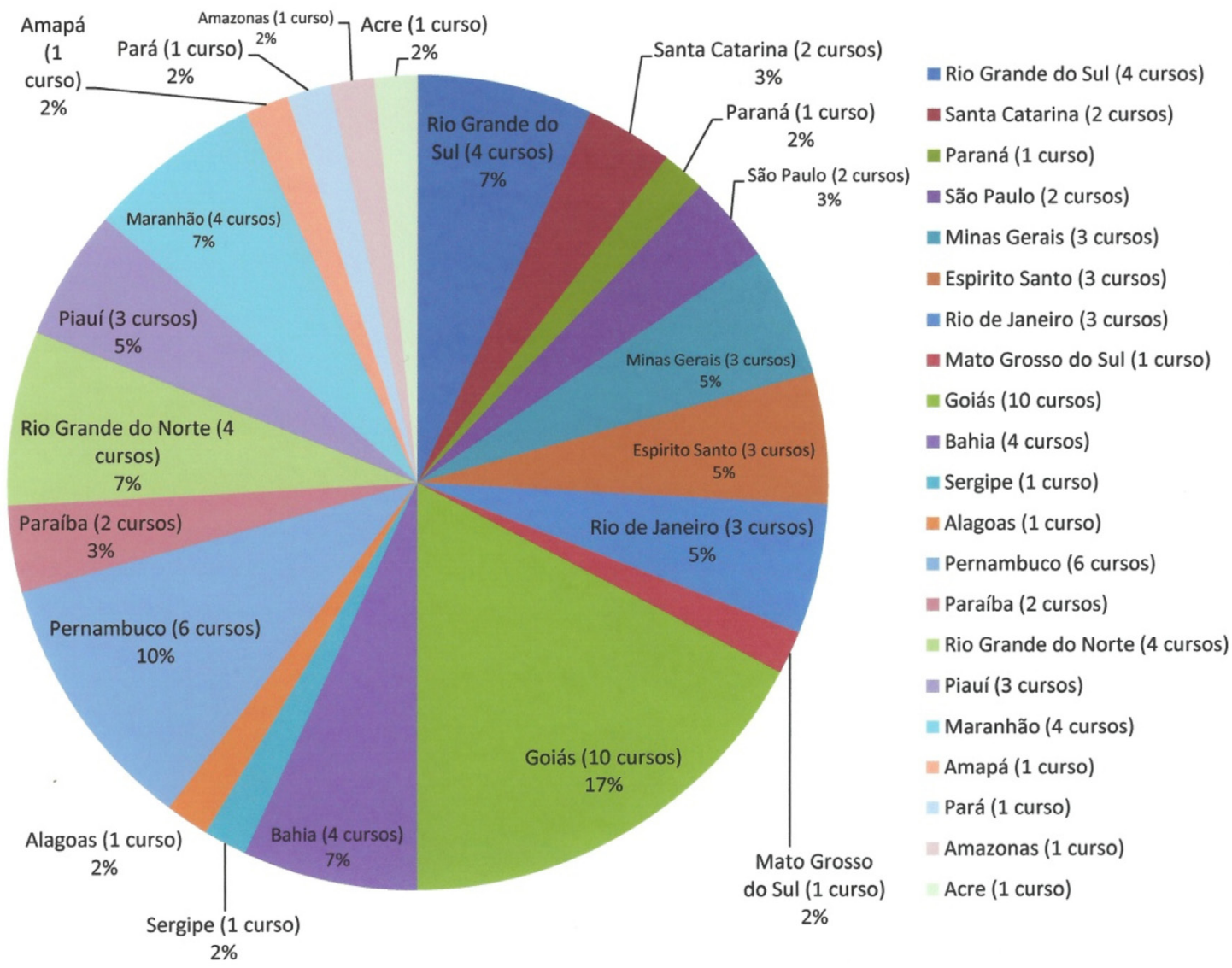

Figura 1S. Cursos de Licenciatura em Química em IF por estados da federação 